\title{
As tecnologias de informação: morte ou vida para as ciências humanas? ${ }^{1}$
}

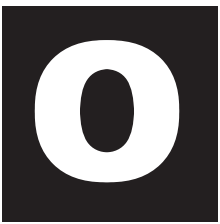
tema de vida e morte é bastante importante em meu trabalho intelectual. Escrevi um livro sobre os acidentes de trabalho, que se chama "Vida e morte no trabalho", no qual desenvolvo a idéia de que o erro que leva ao acidente do trabalho é socialmente produzido, o que resulta - nos casos mais extremos - em morte; nos menos extremos, as pessoas se machucam e, às vezes, só se assustam.

Então, a questão da vida e da morte das ciências sociais e das ciências humanas, a partir do avanço das tecnologias informacionais é, para mim, mais uma questão sobre quais partes das ciências sociais irão sobreviver, por assim dizer, e quais irão morrer. Inicialmente, teríamos que pensar isto em função do avanço das tecnologias informacionais, mas não vou falar sobre todos os movimentos nos campos das ciências sociais, ciências naturais, etc., o que seria outra palestra.

Dentro da minha ótica, existe uma perspectiva muito simples: no momento há duas maneiras distintas nas quais as ciências sociais ou partes delas podem morrer devido ao avanço das tecnologias informacionais. De um lado, temos aqueles profissionais que praticam as Ciências Sociais buscando ignorar o novo (inclusive novas técnicas) não se equipando para tra-

* Professor do Programa de Pós-Graduação em Ciências Sociais da Unicamp. Doutorado na École des Hautes Études en Sciences Sociales em Paris.

1 Palestra proferia na II Conferência Científica da UFRGS. 
balhar com as mesmas (em pesquisas em sala de aula, etc.) e por não se manterem atualizados, arriscam-se a ser ultrapassados pelos colegas que conseguem acompanhar as mudanças e incentivá-las nas suas práticas, e este é o lado óbvio da questão.

As tecnologias informacionais levariam à transformação das disciplinas de modo a fazer com que algumas práticas e técnicas, antes tratadas como centrais, passassem a ser vistas como cada vez menos relevantes, menos respeitadas.

Para sobreviver, seria preciso adaptar-se em relação ao novo. Agora há, também, o outro lado da morte e isto acontece, sobretudo, quando as tecnologias passam a dominar a disciplina, a dominar a perspectiva que as pessoas têm sobre aquilo que elas devem fazer.

O que quer dizer isto? Que as pessoas dizem que se eu não posso usar essas tecnologias, não posso estudar o problema. Ou seja, no meu modo, vemos a idéia de maneira relativamente forte, às vezes, nos Estados Unidos, com os sociólogos, cientistas políticos de orientação quantitativa, que pensam, basicamente, que tudo o que não se pode colocar em números não vale a pena ser estudado.

Então, isto, obviamente, é a morte também de áreas das ciências sociais; os problemas devem sempre guiar nossos trabalhos, e não as técnicas. Falarei dentro deste contexto, sobre a reconstrução das ciências sociais neste mundo cada vez mais "pós-industrializado", cada vez mais "informacional", onde as tecnologias de informação assumem um papel crescente em quase todas as áreas da vida: compras, governo, gestão, sexo...

Para começar, o importante é notar que a adoção de novas tecnologias pode servir como pretexto para se interrogar sobre a atual maneira de se trabalhar, e que essas tecnologias podem servir de pretexto ou impulso para alavancar novas maneiras de trabalho.

No ensino - podemos começar com o exemplo de uma nova tecnologia um pouco antiga, hoje consolidada em muitos campos do saber, mas que 
se inseriu na relação professor/aluno, servindo para modificar a mesma. O exemplo de que vou falar é o desenvolvimento de técnicas de múltipla escolha, ou seja, o desenvolvimento dessas técnicas deixa o professor livre para que os assistentes possam atribuir as notas e até uma correção automática. Às vezes, a opção por provas de múltipla escolha faz com que o relacionamento professor/aluno permita, obviamente, um ensino de massa, ou seja, tecnologia - aqui como tecnologia de modo antigo - tira um gargalo que havia entre a relação professor/aluno, que era como corrigir mais de 30 ou 40 provas. Então esta é a minha primeira idéia de como a tecnologia pode ter um impacto na relação que o cientista social estabelece com o mundo ao seu redor.

Podemos em seguida pensar no exemplo do vídeo. O vídeo permitiu aos professores fazerem "convites" a outros cientistas famosos. Pessoas como Edgard Morin, ou até o falecido Michel Foucault são trazidas para a sala de aula pelos vídeos que têm suas palestras. O vídeo também transformou a maneira de alguns alunos fazerem os seus trabalhos, e em vez de fazerem um trabalho escrito, o que se vê são alunos fazendo vídeos e entregando vídeos. Ou seja, a nossa maneira de perceber e representar o mundo se transformou. Mas essas mudanças aconteceram sob um certo controle do professor. O que me parece que está acontecendo na área de tecnologia de informação é que o professor perdeu um pouco o controle sobre o processo. Apercebi-me disso há um ano e meio quando estava em uma universidade muito informatizada na Inglaterra, e vi todos os CD-Rom, os bancos de dados, etc., e o aluno lá tinha tudo o que ele queria no mundo, era uma situação realmente impressionante.

Não saía da biblioteca, ficava lá até me jogarem na rua! Realmente dava para fazer em um dia, o que fazia aqui em quatro ou cinco dias de trabalho normal, era meio frenética a vida. Perguntei a um colega a respeito dos efeitos da instalação de tecnologias de CD-Rom, de internet, de disponibilidade de bancos de dados enormes, dentro da biblioteca: Qual é a 
situação e o que mudou na relação entre professor e aluno? Ele respondeu, basicamente: "olha, hoje a gente diz para o aluno: F...O, F...O", e eu olhei para ele e disse: "o que é isso?" Desculpa, o termo é em inglês chulo, que significa "Fuck off and find out", ou seja, vai embora e descobre. O que nós temos aqui é que o professor não fornece mais a informação tão necessária no processo de construir o conhecimento. Ele acaba ajudando o aluno a aprender aquilo que descobre no decorrer de suas pesquisas. Quando a gente pensa em qual é a tradicional função do professor, que é a de fornecer informações, espera-se que essas informações se transformem em conhecimento por parte do aluno. O aluno tem que ter a capacidade para ir atrás das informações e uma vez o aluno de posse dessas informações, a função do professor é ajudá-lo a interpretar e entender, ou seja, transformar essas informações em conhecimento. Ou seja, isto é um pequeno exemplo das mudanças.

Podemos fazer uma outra observação: a sala de aula e o modo de pesquisar dos alunos também podem mudar! Por exemplo, a tecnologia da internet permite análises comparadas. No semestre passado, eu na Unicamp e o colega José Eisenberg, na UFMG, experimentamos um curso interinstitucional que se chamava "Ciências Sociais e a sociedade em formação", no qual uma das idéias era de colocar os alunos a analisar os mesmos fenômenos em Belo Horizonte e em Campinas, através de batepapos e troca de correspondências eletrônicas, onde eles teriam a possibilidade de desenvolver noções sobre similitudes e diferenças nos mesmos fenômenos, nas duas cidades: movimentos sociais, a maneira de a Prefeitura tratar a informática, mercado de trabalho, entre outros. Ou seja, aqui temos algo extremamente interessante: a possibilidade de os alunos trabaIharem desde cedo de maneira explicitamente comparativa, em contato direto com colegas de outras instituições e de outras formações, e assim aprender com a ajuda de tecnologias informacionais a importância da análise comparativa. 
Este exemplo, é claro, reúne de um lado o ensino e de outro lado a pesquisa dos alunos. (É preciso dizer que no mundo virtual as idéias são, muitas vezes, mais bonitas que no mundo real, mas não conseguimos implementar os projetos por causa da greve de dois meses que houve nas universidades estaduais paulistas).

Agora vou examinar os campos de "pesquisa" e volto com aquele mesmo professor inglês, que observou outro fenômeno que era crescente - o emprego da informação como força de produção do capitalismo avançado - estava criando novos campos de pesquisa para os cientistas sociais. Uma de suas pesquisas, por exemplo, era sobre as conseqüências da engenharia genética sobre o trabalho na agricultura. Ou seja, como que o trabaIho dos plantadores de tomate muda com a engenharia genética.

É óbvio que existem outros temas, inclusive, sociabilidade virtual, inteligência artificial, ensino a distância, etc., que estão se abrindo. Então, a primeira lição para um pesquisador é que existem campos novos que estão se abrindo em função do avanço da sociedade de informação. Hoje, vemos que uma das técnicas mais básicas das ciências sociais é a análise de conteúdo.

A análise de conteúdo, quando eu fazia como aluno de graduação, era basicamente pegar um jornal, copiá-lo, pegar dois ou três anos ou meses do jornal e, por exemplo, acompanhar como os juízes tratam os criminosos sob a perspectiva da imprensa, e como isso muda ao longo do tempo entre homem e mulher, etc., etc. Era um trabalho extremamente penoso, quem já fez sabe do que eu estou falando, penei, quem não fez, não faça.

Para fazer algum tipo de análise de conteúdo decente no passado necessitávamos de codificadores, treinamento para leitura, treinamento para classificação, para dizer, por exemplo, qual era a perspectiva da imprensa, sobre acidentes de trabalho, que foi uma coisa que Amélia Cohen e os calouros da USP fizeram na década de 80. Ou seja, não sei quanto tempo aquilo lá durou, é muito interessante, mas realmente deve ter derramado muito suor para fazer isto. 
Agora temos o quê? Temos jornais que estão em CD-Rom, podemos fazer uma operação de busca para ver o número de vezes que um certo termo foi citado em determinado período. Talvez usando softwares empregados aqui na UFRGS, pelo José Vicente e sua equipe, também pelos artigos que li na administração e também na lingüística, pode-se também ter uma ajuda automática na pesquisa e na classificação de uma grande variedade de dados qualitativos. Assim, o suor e a chatice, ingredientes tão tradicionais neste tipo de trabalho são, se não eliminados, bastante reduzidos.

Com isto, toda uma série de estudos para quais não tínhamos recursos adequados, no passado, passam a ser viáveis, ou seja, de repente crescem os recursos para este tipo de estudo nas ciências sociais. Usando CDRom de jornais, podemos estudar, por exemplo, diferentes tratamentos de campanhas políticas na imprensa, ao longo do tempo ou no espaço. Como que estão representando em Porto Alegre, em São Paulo, por exemplo, candidatos do PT, do PMDB ou do PFL à prefeitura? Ou seja, pode fazer um estudo sistemático de representações na imprensa a partir de CD-Roms que provavelmente sairiam no final deste ano, ou com um pouco mais de dificuldade, através dos sites da internet.

Como sociólogo, ao estudar as organizações complexas, sempre deparamo-nos com um problema ao chegarmos dentro de uma organização: o excesso de dados. O que você vai escrever em seu caderninho? Como é que você vai tratar as coisas? O que você vai selecionar? Hoje em dia, um sociólogo do trabalho com acesso à organização pode aproveitar esses dados, mas para poder peneirar para analisar ele realmente precisaria, além de uma boa intuição teórica, que sempre é da maior importância, de metodologias informacionais.

Assim, por exemplo, para ajudar a entender todas as intermináveis atas de reuniões ou livros de instruções, poderíamos utilizar o Excel ou uma ferramenta similar para analisar todos os dados quantitativos que as organizações complexas modernas produzem constantemente. Mas, de repente, 
temos instrumentos que podem nos ajudar a captar tantos dados e a gente não queria saber de tanta coisa! No jornal de ontem, O Estado de São Paulo, houve uma outra idéia que vem vindo, choque de transparência, diz a manchete: "vai incluir a internet". Basicamente o governo brasileiro, buscando credibilidade perante as organizações financiadoras internacionais, está querendo que as ações do governo sejam cada vez mais transparentes, cada vez mais possível de serem checadas de fora e de dentro do país. A hipótese é: quando o governo é transparente, maior é a probabilidade de ter crédito, sobretudo para governos de países em desenvolvimento.

Então, isto já está fornecendo novas fontes de dados, como descobrimos ao observarmos o que já está disponível hoje pela internet, tanto pelo Executivo quanto pelos Tribunais. Confesso que não tenho nem a menor idéia de como responder à questão do excesso de dados. Vamos ter muitas informações para analisar. Assim, teremos um problema de morte, se o pesquisador pensar que é suficiente usar apenas esses registros digitalizados para entender, por exemplo, uma organização complexa; isto quer dizer que ele vai esquecer todas aquelas partes da pesquisa tradicional do cientista social que entrevista, que observa, que escuta, etc. Então este é o risco de imaginar que a técnica possa matar outras maneiras de captar informações.

É muito importante reforçar esta idéia sempre. Assim, basicamente, comentei sobre duas coisas: de um lado pesquisadores estão usando a computação para alavancar suas capacidades de sistematização de conhecimentos sobre o mundo. (A busca daquela informação que no tempo teriam requerido muito esforço, agora pode ser feita com muito menos esforço e que no mundo crescentemente digitalizado, temos informações acessíveis que no passado eram acessíveis apenas em papel e agora podem ser tratadas sem ser transcritas, porque já vêm digitalizadas).

Do outro lado, esta informatização generalizada transforma o modo de aprendizagem de ciências sociais, fazendo com que seja muito mais difícil o professor enxergar o seu trabalho como sendo apenas a transmissão 
de informações em sala de aula. O professor de que ser capaz de ajudar as pessoas a usarem as informações disponíveis para compreender o mundo, e isto quer dizer construir teoria. Certas informações sobre este mundo, como avanço das tecnologias, passam a ser muito mais próximas do que no passado, ou seja, eu dei o exemplo da UFMG e a UNICAMP, e com isso, o fato de que a gente possa ter um acesso mais fácil às informações que eram muito distantes no passado, deve ter um enorme potencial reduzir o provincianismo nas nossas disciplinas.

Atualmente, se necessitarmos entender o sistema de privatização da segurança social do Chile, por exemplo, depois de lermos a bibliografia, ainda não entendermos claramente, vamos tentar achar um grupo de alunos no Chile para perguntar-Ihes o que está acontecendo! Antes, obviamente, existiam todos os pretextos para não investigar, hoje em dia com a internet isto mudou.

Agora vou tentar mudar de marcha um pouquinho para falar da questão da inteligência social artificial. Isto, basicamente, é uma idéia que existe principalmente nos Estados Unidos, onde foi patrocinada pela National Science Foundation, que é, em síntese, a aplicação de técnicas de inteligência artificial aos fenômenos sociais. A inteligência social artificial abraça de um lado a análise de dados, e de outro lado a construção de teorias. A idéia começou a se cristalizar em meados da década de 80, em um congresso sobre Inteligência Artificial e Sociologia e que levou à publicação de um livro Ação social e inteligência artificial, de Gilbert e Heath.

A idéia tem influência tanto na antropologia quanto na ciência política mas nesta abordagem de hoje me limitarei apenas à sociologia. Quem está interessado em antropologia, tem um artigo bem interessante de Chablo no Current Antropology, de 1966.

Então, primeiro, vamos falar sobre inteligência artificial sem o social. Os pesquisadores nesta área têm ignorado a sociologia, a disciplina ciência cognitiva, que é absolutamente enraizada na inteligência artificial; ignoram 
basicamente a sociologia interacionista. A sociologia interacionista trata de nossa compreensão do mundo, mas o desafio da inteligência artificial era sempre o de aplicar o comportamento de um ou mais atores humanos, e não o ator humano em uma relação social.

Estamos no começo de um processo de desenvolvimento de inteligência artificial e este campo pode abrir novas áreas de pesquisa para os sociólogos. Pessoalmente, sou bastante cético quanto à possibilidade de desenvolver uma inteligência artificial na qual a máquina imita o comportamento dos seres humanos em sociedade, sem recorrer à sociologia. Ou seja, com toda a ciência cognitiva do mundo, você não vai conseguir modelar a ação social sem estudar as interações sociais. Essa idéia não é nova, Randall Collins defendeu-a em 1992, e também Newell em seu livro Unified theories of cognition. Ou seja, existe uma contribuição que a sociologia pode trazer ao desenvolvimento da inteligência artificial.

Então eu volto agora para a inteligência artificial na pesquisa. Quando usamos um programa de busca na internet, este programa procura as palavras digitadas, eu sociólogo estudioso do trabalho e digitaria, por exemplo: trabalho, estatística, Brasil. O que chegaria à minha casa? Milhares de documentos, muitos dos quais não têm nada a ver com aquilo que estou procurando. Vocês todos conhecem esse fenômeno. Agora, não sei se alguém tem aqui a felicidade de usar o computador Macintosh, mas a partir do sistema 8,5 e, sobretudo, o sistema 9,0, você tem uma hipermáquina de busca Sherlock, dotada de inteligência artificial, que já elimina muito do lixo justamente por causa deste nível superior de inteligência; o programa adivinha um pouco o que você está buscando.

No futuro, vamos ter agentes inteligentes que vão ser comercializados e que vão copiar nossos próprios mecanismos de busca dos documentos. Ou seja, quando chega todo aquele lixo, trabalho, estatística, Brasil, a máquina vai aprender o que selecionamos para na próxima vez não trazer o mesmo tipo de documento, vai aprender conhecendo a nossa maneira de 
incluir ou de eliminar coisas. Eu não sei se alguns de vocês leram Caderno Mais, da Folha de São Paulo de domingo, umas seis ou oito semanas atrás, teve uma matéria de capa sobre o supercérebro. Este era basicamente sobre a idéia de sistemas de conhecimento distribuído e está sendo criado em Los Álamos, ou seja, aqui se está falando de inteligência artificial de novo. O servidor Principia Cybernetica Web, é capaz de reconstruir continuamente os links entre as suas páginas para se adaptar às necessidades dos usuários. Esse servidor coloca novos hiperlinks onde acha que esses serão úteis aos navegantes e tira os links antigos. O resultado é um sistema dinâmico de fortalecimento e de enfraquecimento de links entre as diversas páginas. É mais ou menos como o funcionamento do cérebro, ou seja, lembramos como chegar em casa, vamos lá todos os dias, então aqueles links todos estão lá presentes. Agora se tentarmos lembrar, por exemplo, da casa que moramos há um mês, há uns cinco anos, obviamente aquelas memórias estão mais fracas. Então, basicamente, a máquina tenta ligar as coisas que nos tocam, nos preocupam, e tira as coisas que não nos preocupam. A rede ou o HD vai se organizando para adaptar aquilo que as pessoas esperam dela.

Eu não sei se alguns de vocês usam a Amazon, mas quando um cliente estabelecido entra vem uma pequena lista assim: olha pessoas como você compraram tais livros nas últimas semanas, ou seja, é um tipo de agente inteligente que tenta antecipar sua busca novamente. Então, vocês lembram que eu falei, por exemplo, do governo brasileiro, com todos esses dados que estão na internet. Começamos a pesquisar com isto, com a ajuda de um agente inteligente, que vai provavelmente conseguir imitar um pouco a nossa maneira de pesquisar e fazer com que a nossa pesquisa seja bem mais rápida do que o normal, e quando entrarmos em uma área ainda não explorada, teoricamente ele vai aplicar um pouco as mesmas regras usadas em uma outra área para tentar buscar as informações com maior velocidade e eficácia. 
Então, esse desenvolvimento de agentes inteligentes me parece promissora para nossas disciplinas. Não vou entrar em uma análise das diferentes técnicas de inteligência artificial, têm realmente várias, e tudo isso é uma outra discussão.

Podemos identificar três áreas de uso de inteligência social artificial, construção de teoria, ensino e pesquisa. Eu vou começar com a pesquisa.

Desde a década de 60, pesquisadores estão desenvolvendo programas de computação que entrevistam, de Sherry Turkle, o último livro dela, a Vida na tela, na tradução do título, conta um pouco desta história. É de como psicólogos clínicos começaram a desenvolver agentes inteligentes robôs - para entrevistar pacientes online e de como, apesar das resistências iniciais, este tipo de prática se espalhou. Eu sei que aqui no Brasil uns psicólogos não são favoráveis ao uso deste tipo de ferramenta.

Eu tenho que admitir que acho esta idéia de ser entrevistado por um robô meio estranha, mas a bibliografia destaca três vantagens deste tipo de abordagem. A primeira delas, explicada pelo Kinik e seus co-autores, onde ele nota que para temas sensíveis ou embaraçosos usando um robô para fazer entrevista, pode-se ter respostas que são melhores do que em uma entrevista pessoal. Eu acho isso muito interessante, pois seriam temas sobre sexualidade humana, por exemplo, talvez temas sobre a corrupção, onde a presença do entrevistador intimida o entrevistado. Então esse é o primeiro ponto, existem áreas onde parece-me ser uma técnica bastante eficaz.

Segundo, em um futuro próximo, isto realmente é uma novidade, as técnicas de ministrar pesquisas do tipo "survey" podem mudar por causa da internet. Hoje, podemos dizer que em nenhum país o número de assinantes na internet ainda é suficiente para permitir que ela seja usada para substituir o formulário, o entrevistador e a caneta do "survey". Mas nos Estados Unidos, temos informações de que este tempo está prestes a terminar. As experiências mostram que quando se conhece o computador e a 
conexão de graça, consegue-se usar a internet, com quase o mesmo grau de confiabilidade, do que fazer um "survey" no estilo tradicional. Agora talvez vocês digam: "mas é muito caro isso!". Mas vamos pensar no custo de mandar um entrevistador duas, três, quatro vezes e bater na mesma porta, que é isto o que acontece quando você faz um "survey". E não temos realmente algo novo, e isso vai transformar em muito a nossa capacidade de acesso às informações, e a emissão de análises vai sair muito mais rapidamente do que hoje (embora confesso que não entendo como a Datafolha consegue colocar os resultados de seus "surveys" no jornal com tanta rapidez).

A terceira vantagem em relação ao questionário tradicional, é que quando você pesquisa através da internet, os dados podem ser manipulados de maneira diferente, ou seja, quando você codifica todas as respostas de pesquisa no papel, depois joga no Excel, às vezes você perde a ligação entre as variáveis. Enquanto você usa essa tecnologia, a organização passa a ser matricial, os dados se organizam em nódulos na bibliografia sedimenta o significado disso. Obviamente quando você fazendo uma entrevista online tem a possibilidade de recorrer a hipertextos, ou seja, de repente você responde não a uma certa pergunta, em vez de pular quarenta páginas de questões impressas, você vai imediatamente para aquela questão 59, porque respondeu a questão quatro de maneira negativa. Isto é uma outra vantagem.

Então são, vamos dizer, maneiras nas quais essas novas tecnologias vão transformar a maneira de fazer a entrevista.

Também temos a análise assistida por computador de textos escritos. Ou seja, essas pesquisas que o José Vicente e sua equipe estão fazendo, a gente entrevista muito, muitas vezes as entrevistas são extensas, talvez esses programas de computador vão ser tão importantes para o futuro de pesquisas qualitativas, quanto foi o desenvolvimento de programas tipo SPSS para análise de dados quantitativos no passado. Mas vimos anteriormente 
que o leque de documentos possível de ser analisado é grande, partes nãográficas de páginas na WWW, jornais em CD Rom, anais de congressos, relatórios de organizações, interações na internet. Tenho uma aluna na Unicamp que está basicamente tentando traçar a vida social nos bate-papos, bate-papos estruturados em IRC e ela tem basicamente horas e horas de conversas digitais gravadas. É tanto material que é meio difícil de usar as técnicas tradicionais de análise, mas agora como está tudo digitalizado, ela usa peneira do NUD-IST, e isto a ajuda a descobrir coisas que ela não consegue enxergar quando está lendo as entrevistas.

De repente estudos de partes de vida online viram mais fáceis porque já podemos gravar tudo, já podemos colocar os textos digitais em uma máquina. Detestaria se de repente um monte de alunos de mestrado, de iniciação científica, preguiçosos decidissem estudar internet só porque os dados já são apresentados em forma digital. Isto seria a morte.

Voltando um pouco para a inteligência social artificial, temos uma área promissora, onde as teorias básicas são simples e formais. Quando temos teorias simples e formais, isso nos permite modelar o comportamento. Na área de relações internacionais, Mills desenvolveu um sistema especialista, baseado em regras para analisar as negociações, em seguida, aplicou isto na análise de negociações entre a China e a antiga União Soviética. O programa pergunta ao cientista social sobre o que está acontecendo em certos momentos da negociação, usando inteligência artificial e as respostas para ajudar a avaliar o comportamento que está sendo observado. Temos programas mais conhecidos, tipo SIM CITY, tentativa de modelar o gerenciamento de uma cidade, temos também o Growing Artificial Societies, de Epstein e Axtell, sobre o qual pretendo falar depois.

Vocês talvez estejam dizendo, mas tudo isso é coisa velha. Na realidade, as ciências sociais sempre tentavam sistematizar e modelar fenômenos sociais, mas fizemos isto na base de leitura de textos, de codificação, etc. Temos coisas que são muito interessantes feitas nessa base. Eu adoro 
citar esboços feitos de sistematização de dados etnográficos na antropologia. Murdock pegou centenas de etnografias, codificou tudo sobre as relações de parentesco, como as pessoas vivem, como que as sociedades se estruturam sobre diversas dimensões.

Bom, lembro-me de ter descoberto uma coisa muito interessante a partir do estudo de Murdock, é uma coisa que eu não imaginava. O fato era que em todas as sociedades onde tinha observado a respeito, os maridos têm relações fracas com suas sogras, ou seja, isso vai de alguns povos na Austrália, o homem tem que se matar se ele encontra com a sogra, até as sociedades ocidentais onde apenas se faz piada com o assunto. Agora eu acho isso absolutamente fascinante, ou seja, estudos de mais de duzentas sociedades e todos codificados. O que é a relação homem com a sogra? A explicação da teoria triática desenvolvida pelo Caplow ajuda a entender isso. Basicamente, a teoria triática diz que quando você tem uma relação a três, essa relação vai sempre se recompor em uma relação de dois contra um. Então qual é a explicação? Obviamente, a mulher tem uma relação muito próxima com sua mãe e tem uma relação, espera-se, muito próxima com o marido. Isto a coloca em uma tensão intolerável, relação a três, pois ela tem que se decidir se fica com a mãe ou fica com o marido. Então a capacidade de estabelecer formas de vida social a partir da leitura de muitos estudos empíricos e de teorizar a respeito destas formas é, obviamente, algo bem interessante.

Temos outros exemplos deste tipo, que eu gosto muito é do Hudson, que analisou uma centena de monografias sobre locais de trabalho. Ele classificou cinco tipos de gestão e foi observando, dentro das monografias, a relação entre tipo de gestão e outras variáveis. Ele ensinava análise de conteúdo na sociologia do trabalho durante anos e seus alunos leram e codificaram os estudos. E basicamente o que ele descobriu é que onde se têm relações de trabalho participativas, as monografias mostram uma maior satisfação, melhor harmonia, etc., de que todas as outras formas de gerenciamento, fora o gerenciamento classificado como artesanal. 
Ou seja, é possível produzir um conhecimento bastante robusto, porque está baseado em observações independentes das conclusões que vão na mesma direção. Então a gente pode começar a pensar, por exemplo, se pegássemos as dissertações de mestrado na área de agricultura no Brasil, digitalizássemos tudo, o que obteríamos? Ou seja, tem um potencial aqui, eu não quero exagerar o potencial, digitalizar todas as dissertações de mestrado seria uma coisa muito penosa, quando você escaneia as coisas tem que corrigir, etc., tem muita mão-de-obra nisto, mas realmente estamos entrando em uma época onde temos uma capacidade, com ajuda da técnica, de pegar muitos estudos dispersos e chegar a observações consistentes entre os estudos, e em seguida, irem direção àquilo que todos nós prezamos que é a produção de idéias teóricas ambiciosas.

Tecnologias de inteligência artificial copiam a atividade humana. A vantagem é a economia de tempo e o fato de poder verificar facilmente as hipóteses. Ou seja, eu quero investigar uma nova hipótese e não preciso reler tudo, simplesmente coloco na peneira e rodo.

$\mathrm{Na}$ área de análises estatísticas, também podemos esperar avanços. O pesquisador iniciante pode contar com um programa chamado Statistical Navigator, que o ajuda a decidir quais técnicas de análise estatística são melhores para seu projeto. Isso o ajuda a construir seu projeto baseado em uma entrevista informatizada sobre os objetivos e prioridades da pesquisa, ou seja, um CD-Rom que vai te perguntando o que quer fazer? Qual o tipo de população a ser estudada? Que tipo de generalização vai ser feita? E o programa vai te indicando que tipo de técnica deve adotar. Após esta entrevista computadorizada, uma série de alternativas é apresentada ao pesquisador, que através do hipertexto consegue descrições de cada método a que servem de apoio à tomada de decisão.

Obviamente, o Statistical Navigator pode também servir como um elemento de apoio no ensino de métodos e técnicas. Há também na área de ensino, outras possibilidades com conseqüências bem mais radicais do 
que a chegada do vídeo em sala de aula, que transformou o ensino, sobretudo na antropologia. Na Universidade Carnegie Mellon, desenvolveu-se um sistema chamado de entrevistas sintéticas para aprender sobre a vida de um teórico, ou a teoria desse teórico. Você entra em uma coisa meio esquisita, algo que parece uma videoconferência com o teórico. Usa-se um sistema de entrevistas gravadas e perguntas em linguagem natural, e depois a inteligência artificial formata a pergunta de modo que corresponda a uma resposta pré-gravada. A última vez que eu li a respeito disso, só tinha um teórico disponível, que era Einstein, mas Carnegie Mellon é uma universidade muito interessante, do ponto de vista do desenvolvimento da tecnologia, a idéia era de desenvolver outras entrevistas.

Temos mais uma inovação na área de ensino que muitos professores adoram, que programas podem ministrar provas. Nós temos Erving, um programa desenvolvido nos Estados Unidos, que simula a perspectiva de Erving Goffman: o usuário vai do palco aos bastidores, que são conceitos de Goffman, e ele assiste a interação de pessoas virtuais, e vai aprendendo em termos goffmanianos, sobre os sistemas de interação social. O computador pode também testar a compreensão que o aluno da teoria de Goffman. Ou seja, um tipo de prova de múltipla escolha refinado, com resultados corrigidos na hora, de graça! Comentário: alguns desses técnicos de inteligência artificial vão com certeza chegar às salas de aula, um pouco do mesmo modo que os CD Roms chegaram às escolas, transformando o ensino de línguas.

As universidades particulares no Brasil, com seus recursos financeiros, suas posturas propagandistas e desejos de reduzir custos, provavelmente vão ser os primeiros a adotar estas tecnologias. Já podemos ver, por exemplo, o ensino pela internet mais visível no desenvolvimento de cursos tipo MBA, não só no Brasil, mas fora também. Minha pergunta é: qual vai ser a resposta das universidades públicas. Acho que precisamos pensar e refletir sobre isso. Na formulação da minha resposta acho que é essencial refletir 
sobre o papel do professor. Antes, porém, faço uma observação, uma das ironias de automatização de processos de trabalho, é sempre que você automatiza aquilo que é rotineiro. Agora há partes de tarefas que você não pode automatizar, então este trabalho sobra para quem? Para o ser humano. Então com o desenvolvimento da informática como ferramenta de pesquisa, como ferramenta na sala de aula, qual vai ser o papel do professor? O professor provavelmente, isto é ironia, vai virar mais importante ao invés de menos, porque ele vai ser o intermediador entre todas as informações e a construção do conhecimento da parte do aluno. O professor não transmite mais a informação, ele ajudará o aluno a compreender e a compreensão se faz através de entendimento e construção de teoria. Então agora, eu vou para a questão de construção de teoria.

Essas técnicas de análise que estão sendo usadas servem para testar hipóteses de pesquisadores, mas servem também para gerar novas hipóteses. A partir do momento em que o pesquisador constrói inter-relações entre hipóteses verificadas, estamos falando de construção de teoria. Mas existem também outras facetas, e uma delas e a construção de agentes, formas de vida artificial que podem simular comportamento, por exemplo, de animais tais como as formigas. Mas existem também as tentativas, em vez de tentar simular comportamentos de formigas simular o comportamento de seres humanos, eu não estou falando de ações, estou falando de comportamentos, que é algo muito diferente. Ou seja, produzem modelos computacionais que simulam o que acontece em sociedades em caso de guerra, fome, desastres. São reações quase biológicas do ser humano que são modeladas, não são ações e interações sujeitas calculadas racionalmente. São situações de interação social. Esses modelos são baseados em comportamentos humanos já observados, por exemplo, o que aconteceu com a fome em Bihar, na Índia, o que aconteceu em Biafra, o que aconteceu na grande fome da China. E é assim que se constroem os modelos, e os modelos funcionam no futuro mais ou menos porque representam comportamentos observados no passado. 
Assim, a inteligência artificial aplicada à sociedade tenta modelar comportamentos do ser humano. E, para concluir, procurei, nesta apresentação, ir lá na frente e trazer algumas idéias de tecnologias, produtos da sociedade de informação, que podem contribuir para a transformação da maneira na qual fazemos nossas ciências sociais. Como professores, como pesquisadores e como teóricos. Uma coisa é certa: as qualificações dos sociólogos e outros cientistas sociais vão ter que mudar para poderem incorporar essas mudanças tecnológicas. Também haverá, com certeza, uma aproximação entre a Sociologia e as Ciências Sociais, e as Ciências da Computação. Eles precisam de nós para pensar sobre a adequação de seus projetos aos sistemas sociais, por exemplo, para desenvolver a inteligência artificial como colocado aqui, mas nós também precisamos deles, e muito, seja para modelarmos, por exemplo, precisamos de cientistas da computação para produzir agentes que possam ajudar nossa pesquisa. A interface entre as Ciências Sociais e a Ciência da Computação vai crescer. Imagino que os cientistas da computação hoje em dia estão sendo assediados. Na Faculdade de Direito por exemplo, os juristas e advogados. E aqui na UFRGS podemos ver que as Ciências Sociais precisam deles. Também vão ser necessários investimentos na infra-estrutura das universidades e quem sabe uma redefinição das qualificações dos cientistas sociais.

Além de conhecer a teoria e métodos tradicionalmente ensinados e SSPS, o aluno terá que conhecer bibliotecas virtuais NUD.IST e outros recursos. Para poder trabalhar à vontade, o pesquisador teria que ter o acesso quase sem restrições a essas ferramentas. Agora, nem tudo a respeito do qual eu falei vai entrar em prática. Os autores sempre prometem muito mais do que conseguem entregar, e o perigo é sempre ser levado a um beco sem saída, por causa da propaganda, por causa dos modismos. Existe, e aqui eu abandono um pouco o foco anterior sobre inteligência artificial e outras tecnologias, existe uma rede mundial de computadores, existem muitos CD-Roms espalhados pelas bibliotecas de ciências sociais no Brasil, existem bancos de dados por toda parte, temos um projeto "Prossiga" de 
bibliotecas virtuais (que ainda está triste na nossa área) estão brotando sites na internet com muitos dados, relatórios e até dados comparados (por exemplo, quem quer estudar eleições no mundo, há sites que têm os resultados de eleições nas democracias contemporâneas).

O desafio é juntar essas fontes de informações tão dispersas, de maneira a melhorar o acesso à informação dos cientistas sociais brasileiros, e usando técnicas tradicionais e novas, inclusive inteligência social artificial, contribuir na melhoria de nossa ciência.

No futuro, algumas partes da sociologia que hoje gozam de grande destaque, vão morrer. Os fatos matam as ideologias. Na medida em que podemos ter mais fatos, acesso a mais informações para testar nossas hipóteses será tanto mais difícil para pessoas que têm uma visão essencialmente ideológica da ciência social sobreviverem, acho eu. Em compensação, outras partes da ciência social passarão a se desenvolver, ou seja, alguns morrer e outros nascem. Assim que é a ciência, assim que é a vida, mas a vida continua, sempre se regenerando, sempre se recriando, e as ciências sociais também, embora em condições diferentes.

Recebido para publicação: 10/06/2004 Aceite final: 10/07/2004 